\title{
Effects of oral amino acid cystine (700 mg) and theanine (280 mg) administration on SARS-CoV-2 virus infection - A case series
}

\author{
Hiroaki Tanno ${ }^{1}$, Michinaga Takahashi ${ }^{1}$, and Takashi Tsuchiya ${ }^{2}$ \\ ${ }^{1}$ Towada City Hospital \\ ${ }^{2}$ Public Interest Incorporated Foundation Sendai City Medical Center
}

October 5, 2020

\begin{abstract}
An amino acid supplement containing $700 \mathrm{mg}$ of cystine and $280 \mathrm{mg}$ of theanine was administered to 4 patients during the treatment of SARS-CoV-2 virus infection. Negative reactions on polymerase chain reaction (PCR) testing were promptly obtained. Oral ingestion of cysteine and theanine $(\mathrm{C} / \mathrm{T})$ may promote SARS-CoV-2 virus elimination.
\end{abstract}

\section{Introduction}

COVID-19 is an infectious disease caused by the SARS-CoV-2 virus.[1] The treatment has not been established and vaccine development is delayed. Internationally, the number of SARS-CoV-2-infected patients exceeds 25,000,000. In Japan, [?]70,000 persons have been infected and the number of patients is increasing.[2]

According to a review of patients who died in Japan, persons aged [?]70 years accounted for $80 \%$. The overall mortality rate is $1.6 \%$, but it increases with age. It is [?]1\% in those aged 10 to 49 years, whereas the rates in those aged 60 to 69 years, 70 to 79 years, and 80 to 89 years are $1.9,5.7$, and $11.5 \%$, respectively; the mortality rate in elderly persons is reportedly [?]10-times higher than in young persons.[3] As immune deficiency is noted in the elderly, it is important to prevent immune deficiency and improve the immunity in the current situation in which treatment has not been established.

Cystine is synthesized through bimolecular binding of cysteine, as a sulfur-containing amino acid, to disulfide. It is contained in many foodstuffs, including meat. After cellular uptake, cystine is reduced to cysteine. Theanine is a tea component, and is decomposed to glutamic acid and ethylamide after being absorbed in vivo. Intracellular cysteine, glutamic acid, and glycine function as substrates for the synthesis of glutathione, which exhibits the most potent antioxidant actions in vivo.[4]

A previous study reported that the simultaneous administration of cystine and theanine $(\mathrm{C} / \mathrm{T})$ stimulated influenza antigen-specific immunoglobulin $\mathrm{G}(\mathrm{Ig} G)$ antibody production via glutathione synthesis in mice. An experiment using old mice also yielded similar results.[5-6] Furthermore, a study involving humans reported that $\mathrm{C} / \mathrm{T}$ administration significantly increased antibody production after influenza vaccination in elderly patients with malnutrition.[7] These findings suggest that $\mathrm{C} / \mathrm{T}$ administration influences the clinical course of SARS-CoV-2 virus infection. We report 4 SARS-CoV-2-infected patients who were admitted to our hospital, and treated using a supplement containing cystine $(700 \mathrm{mg})$ and theanine $(280 \mathrm{mg})$, leading to favorable results.

\section{Subjects and Methods}

The subjects were 4 patients admitted to our hospital under a diagnosis of SARS-CoV-2 virus infection. All patients had positive reactions on polymerase chain reaction (PCR) testing and symptoms such as fever and 
dysosmia. They were hospitalized as mild-status patients. A supplement containing cystine (700 mg) and theanine $(280 \mathrm{mg})$ at a total volume of $1.5 \mathrm{~g}$ was orally administered once a day from X month 15 th until discharge in all patients. While continuing standard treatment, the presence of the virus was examined using PCR testing. After confirming negative reactions on two consecutive sessions of PCR testing, which comprised a criterion for discharge, the patients were discharged. We investigated supplement compliance after the start of administration, PCR testing results, and the interval from the start of supplement administration until negative reactions on two consecutive sessions of PCR testing were obtained.

\section{Case presentation}

Concerning $\mathrm{C} / \mathrm{T}$ adherence, $\mathrm{C} / \mathrm{T}$ ingestion was possible every day in all patients.

Case 1

Patient: A woman in her nineties.

Complaint: Fever.

Medical history: Intestinal obstruction and dementia/hearing loss.

Infectious disease/allergy: Absent.

Present illness: In a nursing-care facility to which she had been admitted, it was clarified that a resident had novel coronavirus infection on X month 8th, 2020. Fever was noted on X month 10th and PCR testing was conducted on the same day. A positive reaction was detected and she was admitted to our hospital on $\mathrm{X}$ month 11th.

Physical examination on admission: The height, body weight, and body mass index (BMI) were $150 \mathrm{~cm}$, $40 \mathrm{~kg}$, and 17.78, respectively. The blood pressure, pulse rate, and body temperature were $121 / 59 \mathrm{mmHg}$, $71 / \mathrm{min}$, and $36.8^{\circ} \mathrm{C}$ (after the oral administration of Acetaminophen), respectively.

Laboratory data on admission: Chest X-ray did not demonstrate pneumonia. The TB, AST, ALT, ALP, LDH, $\gamma$-GTP, ChE, TP, Alb, Cr, BUN, and CRP levels were $0.26 \mathrm{mg} / \mathrm{dL}, 20 \mathrm{IU} / \mathrm{L}, 10 \mathrm{IU} / \mathrm{L}, 230 \mathrm{IU} / \mathrm{L}, 218$ $\mathrm{IU} / \mathrm{L}, 16 \mathrm{IU} / \mathrm{L}, 256 \mathrm{IU} / \mathrm{L}, 6.9 \mathrm{~g} / \mathrm{dL}, 3.6 \mathrm{~g} / \mathrm{dL}, 0.79 \mathrm{mg} / \mathrm{dL}, 13.3 \mathrm{mg} / \mathrm{dL}$, and $0.30 \mathrm{mg} / \mathrm{dL}$, respectively. The HbA1c value, WBC, RBC, Hb level, Ht value, PLT count, PT-INR, D-dimer level, and ferritin level were $5.6 \%, 4,000 / \mu \mathrm{L}$ (Neut/Lymp=1.19), $438 \times 10^{4} / \mu \mathrm{L}, 12.9 \mathrm{~g} / \mathrm{dL}, 39.4 \%, 26.5 \times 10^{4} / \mu \mathrm{L}, 0.92,3.3 \mu \mathrm{g} / \mathrm{mL}$, and $169.3 \mathrm{ng} / \mathrm{mL}$, respectively.

Course after admission: Slight fever $\left(37.0\right.$ to $\left.37.9^{\circ} \mathrm{C}\right)$ persisted, but fever $\left(>38^{\circ} \mathrm{C}\right)$ was sometimes observed. The CRP level ranged from 4 to $5 \mathrm{mg} / \mathrm{dL}$. The general condition was maintained, and the patient was discharged on May 21st. No antiviral drug, such as Favipiravir, was used (admission period: 41 days).

$\mathrm{C} / \mathrm{T}$ administration and PCR testing results

One pack/day of $\mathrm{C} / \mathrm{T}$ was administered from $\mathrm{X}+1$ month 15 th, and this was continued until $\mathrm{X}+1$ month 21st. In this patient, negative and positive reactions on PCR testing were repeatedly detected 4 times, but negative reactions on two consecutive sessions of PCR testing were obtained 5 and 6 days after the start of $\mathrm{C} / \mathrm{T}$ administration (Figure a).

Case 2

Patient: A woman in her nineties.

Complaint: Fever.

Medical history: Dementia.

Infectious disease/allergy: Absent.

Present illness: In a nursing-care facility to which she had been admitted, it was clarified that a resident had novel coronavirus infection on X month 8th, 2020. Fever was noted on X month 10th and PCR testing was 
conducted on the same day. A positive reaction was detected and she was admitted to our hospital on $\mathrm{X}$ month 11th.

Physical examination on admission: The height, body weight, and BMI were $136 \mathrm{~cm}, 37.8 \mathrm{~kg}$, and 20.44, respectively. The $\mathrm{SpO}_{2}$ was $96 \%$ (room air). The blood pressure, pulse rate, and body temperature were $156 / 87 \mathrm{mmHg}, 69 / \mathrm{min}$, and $36.8^{\circ} \mathrm{C}$, respectively.

Laboratory data on admission: Chest X-ray did not demonstrate pneumonia. The TB, AST, ALT, ALP, $\mathrm{LDH}, \gamma$-GTP, ChE, TP, Alb, Cr, BUN, and CRP levels were $0.35 \mathrm{mg} / \mathrm{dL}, 36 \mathrm{IU} / \mathrm{L}, 22 \mathrm{IU} / \mathrm{L}, 260 \mathrm{IU} / \mathrm{L}, 181$ $\mathrm{IU} / \mathrm{L}, 24 \mathrm{IU} / \mathrm{L}, 227 \mathrm{IU} / \mathrm{L}, 6.0 \mathrm{~g} / \mathrm{dL}, 3.6 \mathrm{~g} / \mathrm{dL}, 0.47 \mathrm{mg} / \mathrm{dL}, 12.0 \mathrm{mg} / \mathrm{dL}$, and $0.32 \mathrm{mg} / \mathrm{dL}$, respectively. The HbA1c value, WBC, RBC, Hb level, Ht value, PLT count, PT-INR, D-dimer level, and ferritin level were $5.4 \%, 4,600 / \mu \mathrm{L}$ (Neut/Lymp=1.63), $410 \times 10^{4} / \mu \mathrm{L}, 12.8 \mathrm{~g} / \mathrm{dL}, 38.7 \%, 18.3 \times 10^{4} / \mu \mathrm{L}, 0.92,0.9 \mu \mathrm{g} / \mathrm{mL}$, and $91.6 \mathrm{ng} / \mathrm{mL}$, respectively.

Course after admission: As fever persisted, the administration of Ceftriaxon at $2 \mathrm{~g}$ was started on $\mathrm{X}$ month 13th. On X month 14th, the body temperature, respiratory rate, and $\mathrm{SpO}_{2}$ were $38.1^{\circ} \mathrm{C}, 22$ times $/ \mathrm{min}$, and $93 \%$ (room air), respectively. Chest X-ray did not demonstrate pneumonia. Subsequently, fever transiently reduced, but it recurred on X month 18th. Antibiotic therapy was continued and pyretolysis was achieved on X month 20th. The subsequent condition was stable and the patient was discharged on $\mathrm{X}+1$ month 30 th (admission period: 50 days).

No antiviral drug, such as Favipiravir, was used.

$\mathrm{C} / \mathrm{T}$ administration and PCR testing results

One pack/day of $\mathrm{C} / \mathrm{T}$ was administered from $\mathrm{X}+1$ month 15 th. Even after the start of $\mathrm{C} / \mathrm{T}$ administration, positive reactions on PCR testing persisted, and the dose was increased to 2 packs from X+1 month 26th. After 3 days, a negative reaction was obtained for the first time. In addition, two consecutive sessions of PCR testing yielded negative reactions (Figure b).

Case 3

Patient: A woman in her forties.

Complaint: Dysgeusia.

Medical history: Not contributory.

Infectious disease/allergy: Absent.

Present illness: Malaise developed on X month 21st, 2020. Headache, nasal obstruction, mild cough, and slight fever were noted from X month 24th. Dysgeusia was observed on X month 27th. PCR testing yielded a positive reaction and the patient was admitted on $\mathrm{X}$ month 28 th.

Physical examination on admission: The height, body weight, and BMI were $156 \mathrm{~cm}, 46 \mathrm{~kg}$, and 18.90, respectively. The $\mathrm{SpO}_{2}$ was $98 \%$ (room air). Headache, cough, nasal obstruction, and mild dysgeusia were present. Slight malaise was noted. The blood pressure, pulse rate, and body temperature were 122/78 $\mathrm{mmHg}$, $71 / \mathrm{min}$, and $37.5^{\circ} \mathrm{C}$, respectively.

Laboratory data on admission: Chest X-ray did not demonstrate pneumonia. The TB, AST, ALT, ALP, $\mathrm{LDH}, \gamma$-GTP, ChE, TP, Alb, Cr, BUN, and CRP levels were $0.33 \mathrm{mg} / \mathrm{dL}, 16 \mathrm{IU} / \mathrm{L}, 10 \mathrm{IU} / \mathrm{L}, 125 \mathrm{IU} / \mathrm{L}$, $135 \mathrm{IU} / \mathrm{L}, 10 \mathrm{IU} / \mathrm{L}, 230 \mathrm{IU} / \mathrm{L}, 6.3 \mathrm{~g} / \mathrm{dL}, 3.5 \mathrm{~g} / \mathrm{dL}, 0.45 \mathrm{mg} / \mathrm{dL}, 7.8 \mathrm{mg} / \mathrm{dL}$, and $0.10 \mathrm{mg} / \mathrm{dL}$, respectively. The WBC, RBC, Hb level, Ht value, PLT count, PT-INR, D-dimer level, and ferritin level were 2,700/ $\mathrm{LL}$ (Neut/Lymp=0.88), $403 \times 10^{4} / \mu \mathrm{L}, 10.9 \mathrm{~g} / \mathrm{dL}, 32.3 \%, 18.6 \times 10^{4} / \mu \mathrm{L}, 0.91,0.8 \mu \mathrm{g} / \mathrm{mL}$, and $21.5 \mathrm{ng} / \mathrm{mL}$, respectively.

Course after admission: Headache, slight fever, nasal obstruction, cough, and dysgeusia persisted, but the oral administration of Acetaminophen reduced headache. Pyretolysis was achieved on X+1 month 3rd. 
Headache subsided on $\mathrm{X}+1$ month $4^{\text {th }}$ and taste was normalized. Subsequently, mild nasal obstruction and cough gradually reduced, and the patient was discharged on $\mathrm{X}+1$ month 21st (admission period: 24 days).

No antiviral drug, such as Favipiravir, was used.

$\mathrm{C} / \mathrm{T}$ administration and $\mathrm{PCR}$ testing results

One pack/day of $\mathrm{C} / \mathrm{T}$ was administered from $\mathrm{X}+1$ month 15 th and this was continued until $\mathrm{X}+1$ month 21st. The results of PCR testing were negative 5 and 6 days after the start of $\mathrm{C} / \mathrm{T}$ administration (Figure c).

Case 4

Patient: A man in his forties.

Complaint: Dysgeusia.

Medical history: Fracture of the right lower thigh (20 years previously).

Infectious disease/allergy: Absent.

Smoking: Twenty cigarettes x 15 years. Smoking cessation was achieved in the latter half of his thirties.

Present illness: Fever $\left(38^{\circ} \mathrm{C}\right)$ and cough developed on $\mathrm{X}+1$ month 5th, 2020. Malaise was noted on $\mathrm{X}+1$ month 6th. Dysgeusia was observed on $\mathrm{X}+1$ month 7 th. PCR testing was conducted. On the same day, a positive reaction was detected and the patient was admitted.

Physical examination on admission: The height, body weight, and BMI were $168 \mathrm{~cm}, 64 \mathrm{~kg}$, and 22.68, respectively. The $\mathrm{SpO}_{2}$ was $96 \%$ (room air). Nasal discharge and mild cough were present. Slight malaise was noted. Dysgeusia and dysosmia were noted. The blood pressure, pulse rate, and body temperature were $128 / 92 \mathrm{mmHg}, 94 / \mathrm{min}$, and $38.3^{\circ} \mathrm{C}$, respectively.

Laboratory data on admission: Chest X-ray did not demonstrate pneumonia. The TB, AST, ALT, ALP, LDH, $\gamma$-GTP, ChE, TP, Alb, Cr, BUN, CRP, and Zn levels were $0.38 \mathrm{mg} / \mathrm{dL}, 25 \mathrm{IU} / \mathrm{L}, 24 \mathrm{IU} / \mathrm{L}, 128 \mathrm{IU} / \mathrm{L}$, $201 \mathrm{IU} / \mathrm{L}, 38 \mathrm{IU} / \mathrm{L}, 395 \mathrm{IU} / \mathrm{L}, 6.4 \mathrm{~g} / \mathrm{dL}, 3.7 \mathrm{~g} / \mathrm{dL}, 0.83 \mathrm{mg} / \mathrm{dL}, 8.8 \mathrm{mg} / \mathrm{dL}, 1.18 \mathrm{mg} / \mathrm{dL}$, and $51 \mu \mathrm{g} / \mathrm{dL}$, respectively. The WBC, RBC, Hb level, Ht value, PLT count, PT-INR, D-dimer level, and ferritin level were $3,500 / \mu \mathrm{L}($ Neut$/ \mathrm{Lymp}=3.31), 475 \times 10^{4} / \mu \mathrm{L}, 14.2 \mathrm{~g} / \mathrm{dL}, 41.9 \%, 14.6 \times 10^{4} / \mu \mathrm{L}, 1.03,1.0 \mu \mathrm{g} / \mathrm{mL}$, and 175.9 $\mathrm{ng} / \mathrm{mL}$, respectively.

Course after admission: The general condition was stable, but fever, nasal discharge, cough, and malaise persisted. Dysgeusia reduced from $\mathrm{X}+1$ month 10th. Pyretolysis was achieved on $\mathrm{X}+1$ month 13 th. Blood testing revealed slight increases in the CRP, ferritin, and D-dimer levels $(1.27 \mathrm{mg} / \mathrm{dL}, 278.7 \mathrm{ng} / \mathrm{mL}$, and 3.0 $\mu \mathrm{g} / \mathrm{mL}$, respectively), in addition to a decrease in the Zn level $(62 \mu \mathrm{g} / \mathrm{dL})$ on X+1 month 14 th. Chest X-ray revealed a slight peripheral shadow in the right lower lung field. Subsequently, mild cough was present, but the course was favorable. The patient was discharged on $\mathrm{X}+1$ month 27th (admission period: 21 days).

No antiviral drug, such as Favipiravir, was used.

$\mathrm{C} / \mathrm{T}$ administration and PCR testing results

One pack/day of $\mathrm{C} / \mathrm{T}$ was administered from $\mathrm{X}+1$ month 15 th and this was continued until $\mathrm{X}+1$ month 27th. PCR testing yielded a positive reaction 4 days after the start of $\mathrm{C} / \mathrm{T}$ administration, but negative reactions were obtained 11 and 12 days after its initiation (Figure d).

\section{Discussion}

In Japan, COVID-19 was authorized as a designated infectious disease. After infection is confirmed, reporting and admission/isolation are required. In Aomori Prefecture (population: 1,250,000 persons), where our hospital is located, 35 patients with SARS-CoV-2 virus infection have been confirmed. At our hospital, as a medical institution designated for infectious diseases, 14 patients were hospitalized/treated. Criteria for 
discharge at that time included the absence of fever $\left(37.5^{\circ} \mathrm{C}\right.$ or higher), confirmation of a negative reaction on PCR testing [?]24 hours after the confirmation of respiratory symptom relief, and additional confirmation of a negative reaction after [?]24 hours.[8] In this study, C/T was administered to 4 patients admitted to our hospital; symptoms reduced in all patients during the process of virus-disappearance confirmation using PCR testing according to the criteria for discharge. In Cases 1 to 3 , negative reactions on two consecutive sessions were not obtained through 8, 3, and 4 sessions of PCR testing, respectively. In Cases 1 and 3 , negative reactions were obtained on two consecutive sessions of PCR testing after the start of $\mathrm{C} / \mathrm{T}$ administration. In Case 4, negative reactions were obtained on the $2^{\text {nd }}$ and $3^{\text {rd }}$ sessions of PCR testing after the start of $\mathrm{C} / \mathrm{T}$ administration, leading to discharge. On the other hand, in Case 2, positive reactions were detected on two consecutive sessions of PCR testing after the start of $\mathrm{C} / \mathrm{T}$ administration and the dose of $\mathrm{C} / \mathrm{T}$ was increased 2-fold. Subsequently, negative reactions were obtained on two consecutive sessions of PCR testing, leading to discharge. The mean interval from the start of $\mathrm{C} / \mathrm{T}$ administration until the criteria for discharge were met was 9.8 days, being shorter than the pre-administration course. Concerning SARS-CoV-2 virus infection, it was reported that some patients required a long period until negative reactions on PCR testing were obtained. At Fujita Health University Okazaki Medical Center, 90 pathogen carriers without symptoms were investigated, and the median interval until negative reactions on PCR testing were obtained was 9 days, whereas [?]15 days were required in 11 (12\%) of the 90 subjects.[9] According to a report from China, when comparing the results between patients with and without symptoms $(\mathrm{n}=37$ each), the antibody titer was significantly lower in the latter, and the median period during which the virus was detected in the former and latter was 14 and 19 (maximum: 45 days) days, respectively, being significantly different.[10] In the 4 patients treated at our hospital, the antibody test was not conducted, but all patients had a mild status and negative reactions on two consecutive sessions of PCR testing were not confirmed before $\mathrm{C} / \mathrm{T}$ administration, especially in those aged [?]90 years; antibody production may have been low. $\mathrm{C} / \mathrm{T}$ was reported to stimulate influenza antibody production in elderly persons with malnutrition. This suggests that $\mathrm{C} / \mathrm{T}$ also improved the antibody production capacity in patients with SARS-CoV-2 virus infection, aiding in virus elimination. If $\mathrm{C} / \mathrm{T}$ had not been administered, a longer period may have been required until obtaining negative reactions. This was deduced from the results in a small number of patients. In the future, a prospective study involving a larger number of patients must be conducted.

The course of Case 2 suggests that double-dose administration played a role in the negative reactions; therefore, an initial dose of 2 packs/day may be appropriate. A sufficient dose should be examined in the future, but a previous study suggested the safety of administration at 3 packs/day with no adverse reactions.[11]

Furthermore, $\mathrm{C} / \mathrm{T}$ reduces invasiveness. Several studies reported that $\mathrm{C} / \mathrm{T}$ reduced inflammation after highintensity exercise loading in athletes, inhibiting a reduction in NK activity and improving the condition.[1214] A study regarding perioperative $\mathrm{C} / \mathrm{T}$ administration to patients who underwent surgery for gastric cancer noted early recovery from fever, inhibition of increased energy consumption, early normalization of IL-6/CRP, and early recovery from a reduction in the lymphocyte count ratio.[15] An experiment using a mouse small intestine manipulation model also yielded similar results, in addition to inhibition of a reduction in the small intestinal mucosa glutathione level and early behavioral recovery.[16] Furthermore, experiments using rats demonstrated that $\mathrm{C} / \mathrm{T}$ administration reduced the mortality rates after reperfusion following ischemia, in an intraperitoneally-LPS-treated peritonitis model and after systemic irradiation.[17-19] Excessive secretion of inflammatory cytokines (cytokine storm), including IL-6, may be involved in severe COVID-19; C/T administration may also play a role in severe-status prevention and early reduction of inflammation. [20] Therefore, the use of $\mathrm{C} / \mathrm{T}$ earlier than the timing of administration in our patients, i.e., immediately after infection, should be examined.

Recently N-Acethylcysteine(NAC), a precursor of glutathion, has been suggested to prevent COVID-19 associated cytokine storm and acute respiratory distress syndrome by inhibition of IL-6, IL-8, and TNF-

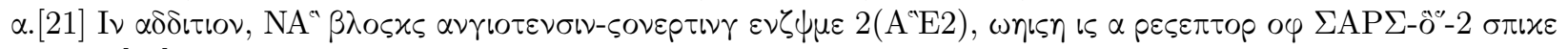

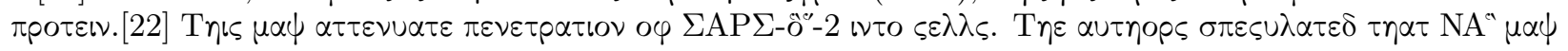

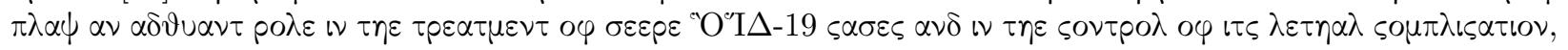




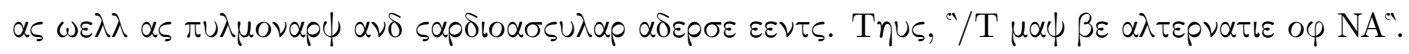

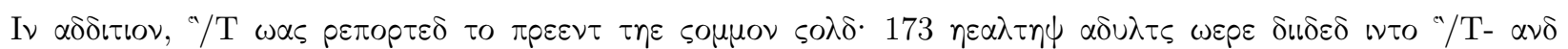

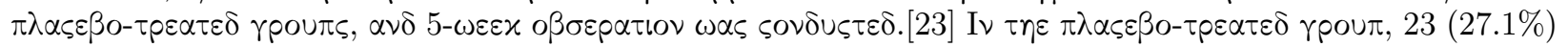

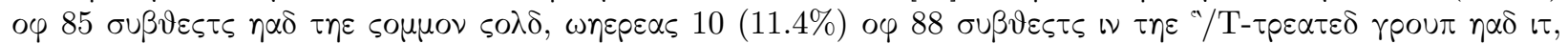

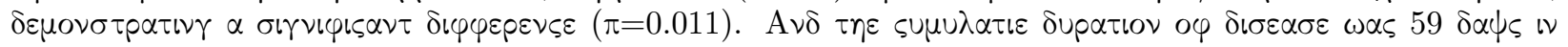

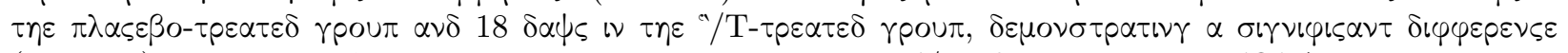

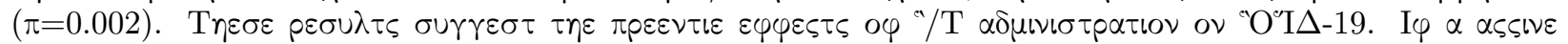

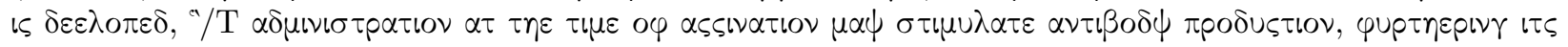
$\pi \rho \varepsilon \varepsilon \nu \tau \varepsilon \varepsilon \varepsilon \varphi \varphi \varepsilon \varsigma \tau \varsigma$.

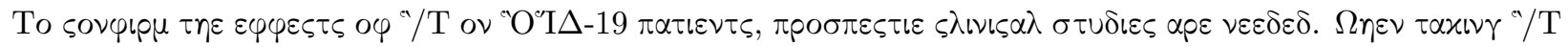

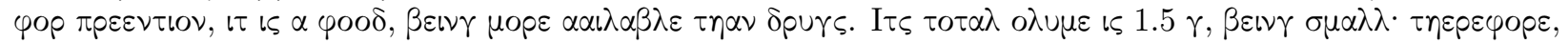

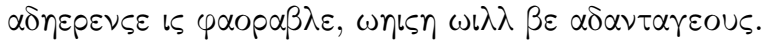

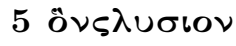

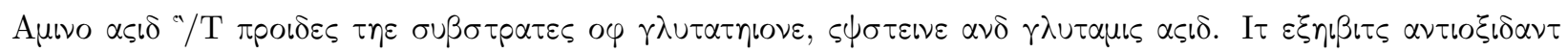

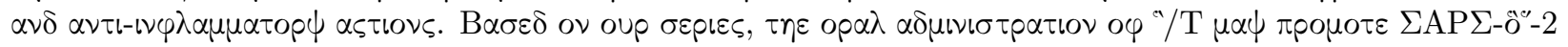

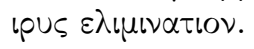

\section{A $\varkappa \nu ० \omega \lambda \varepsilon \delta \gamma \mu \varepsilon \nu \tau \varsigma$}

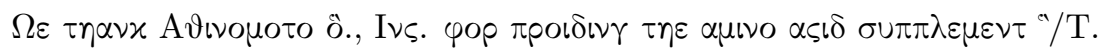

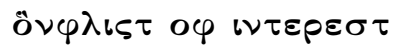

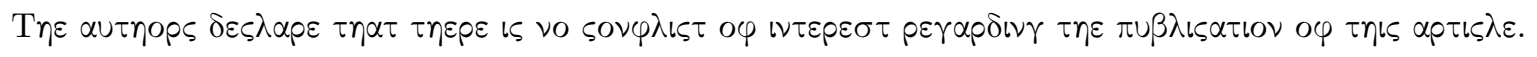

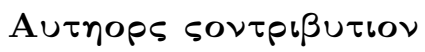

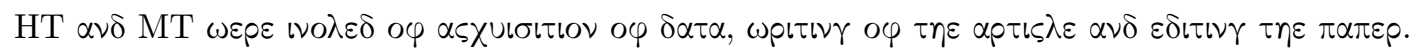

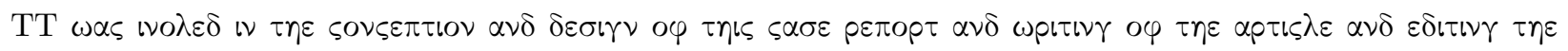
$\pi \alpha \pi \varepsilon \rho$.

\section{ö $\sigma \varepsilon \nu \tau o \varphi \pi \cup \beta \lambda \iota \varsigma \alpha \tau \iota \% \nu$}

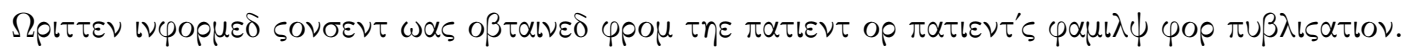

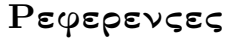

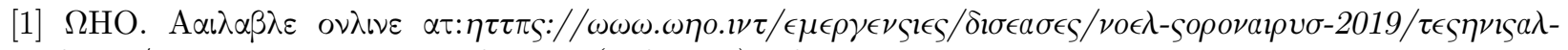
$\gamma v \imath \delta a \nu \varsigma \epsilon / \nu a \mu \imath \nu \gamma-\tau \eta \epsilon-\varsigma о \rho о \nu a \imath \rho v \sigma-\delta \imath \sigma \epsilon a \sigma \epsilon-(\varsigma o \imath \delta-2019)-a \nu \delta-\tau \eta \epsilon-\imath \rho v \sigma-\tau \eta a \tau-\varsigma a v \sigma \epsilon \sigma-\imath \tau$

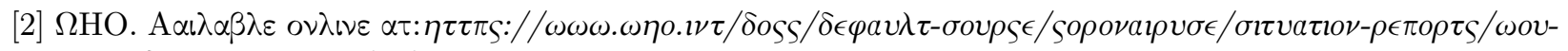
$4-\sigma \epsilon \pi \tau \epsilon \mu \beta \epsilon \rho-2020-\alpha \pi \pi \rho \circ \epsilon \delta . \pi \delta \varphi ; \sigma \varphi \rho \sigma \nu=91215 \varsigma 78 \_4$

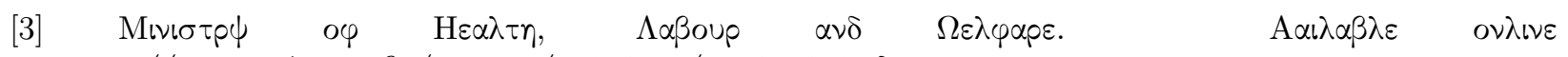
$\alpha \tau: \eta \tau \tau \pi \varsigma: / / \omega \omega \omega . \mu \eta \lambda \omega . \gamma 0 . \vartheta \pi / \varsigma o \nu \tau \epsilon \nu \tau / 10906000 / 000625626 . \pi \delta \varphi$

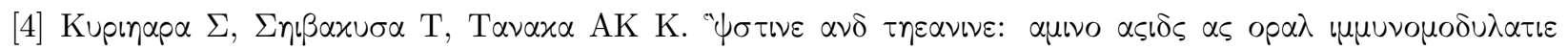

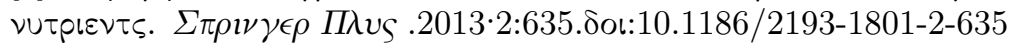

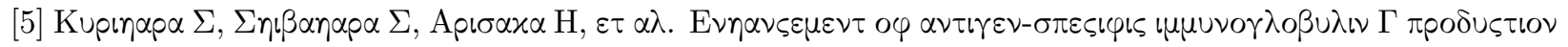

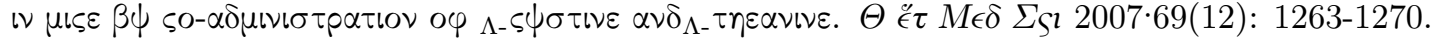

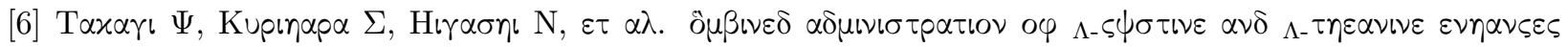

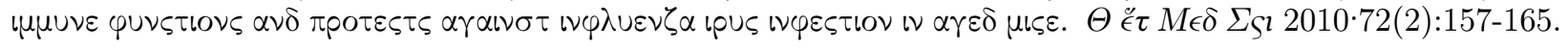




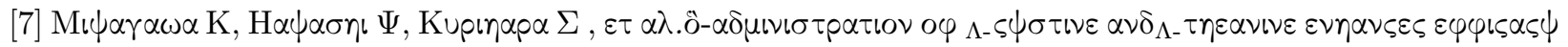

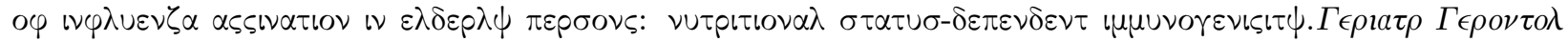
I $\tau \tau$ 2008·8:243-250.

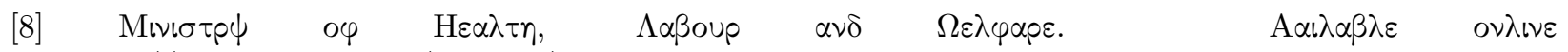
$\alpha \tau: \eta \tau \tau \pi \varsigma: / / \omega \omega \omega . \mu \eta \lambda \omega . \gamma 0 . \vartheta \pi / \varsigma \circ \nu \tau \epsilon \nu \tau / 000618523 . \pi \delta \varphi$

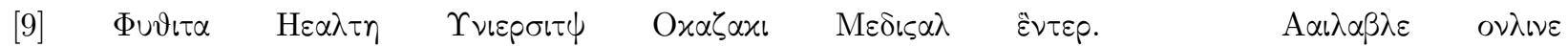

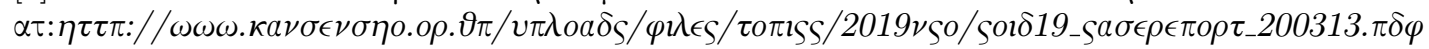

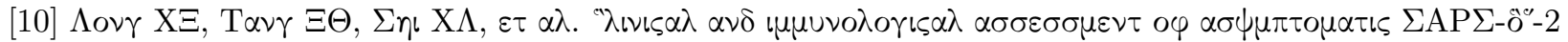

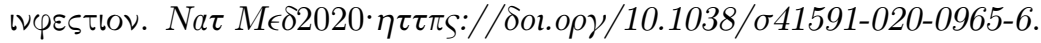

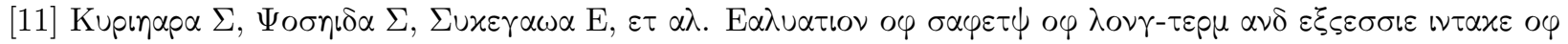

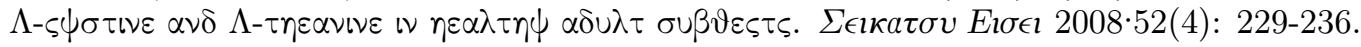

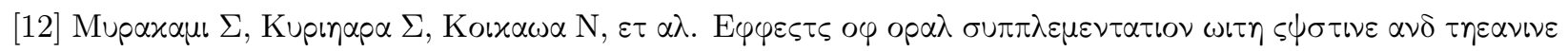

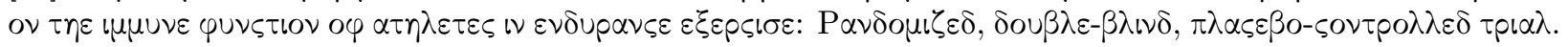

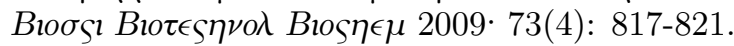

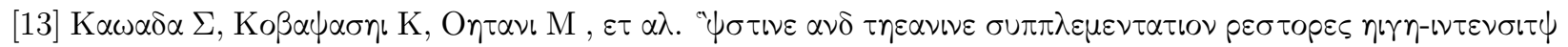

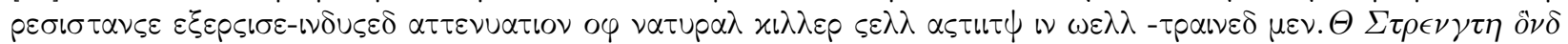
$P \epsilon \epsilon_{S}$ 2010.24(3): 846-851.

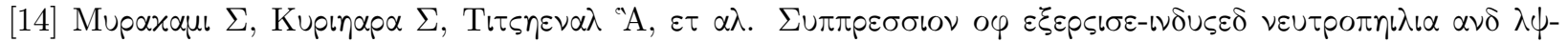

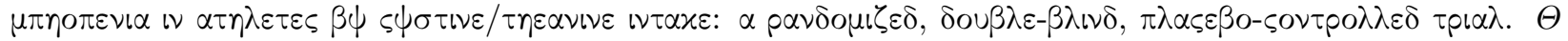

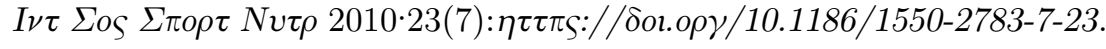

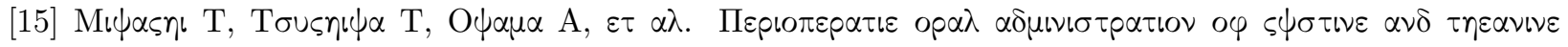

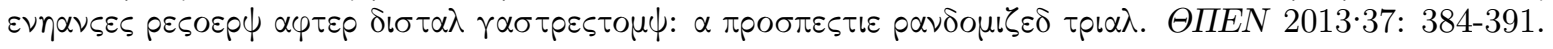

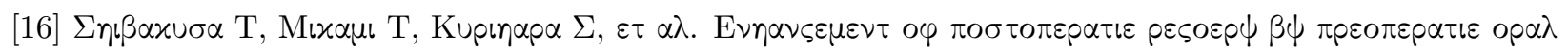

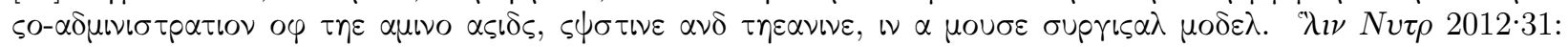
555-561.

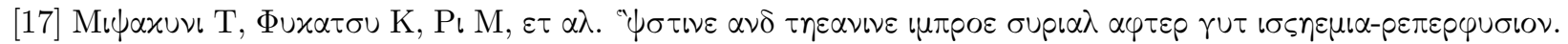

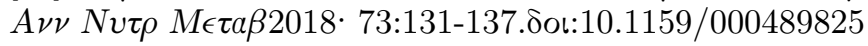

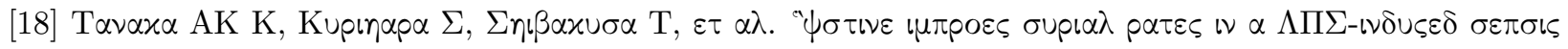

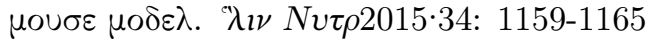

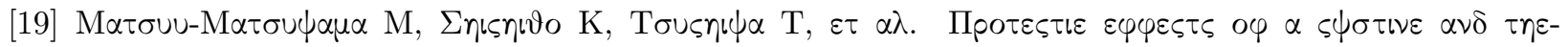

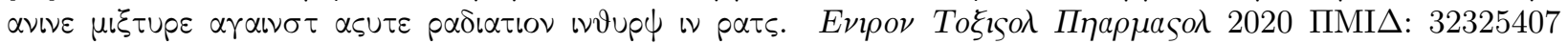

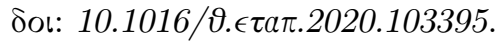

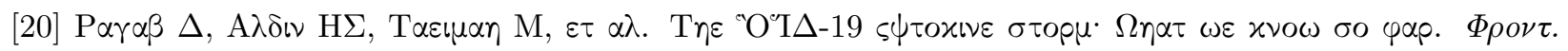

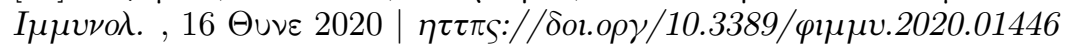

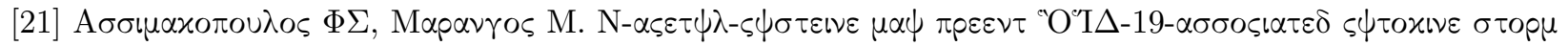

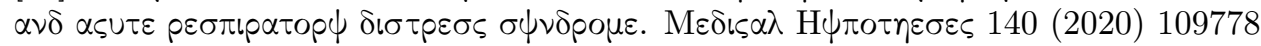

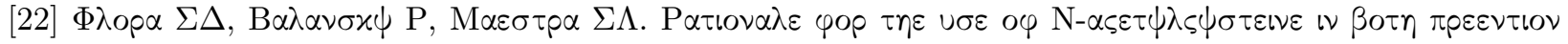

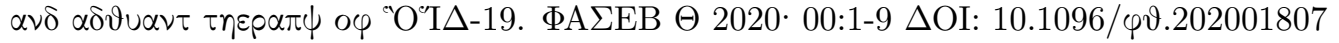

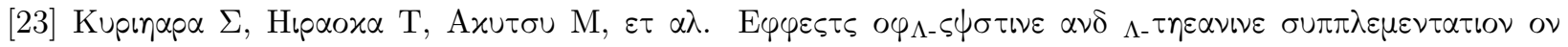

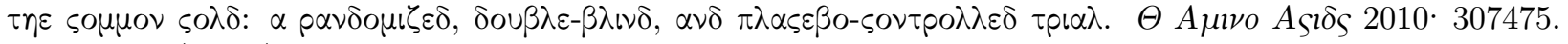
ठol:10.4061/2010/307475.

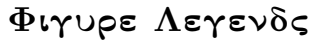




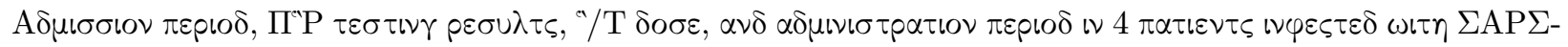
O"-2

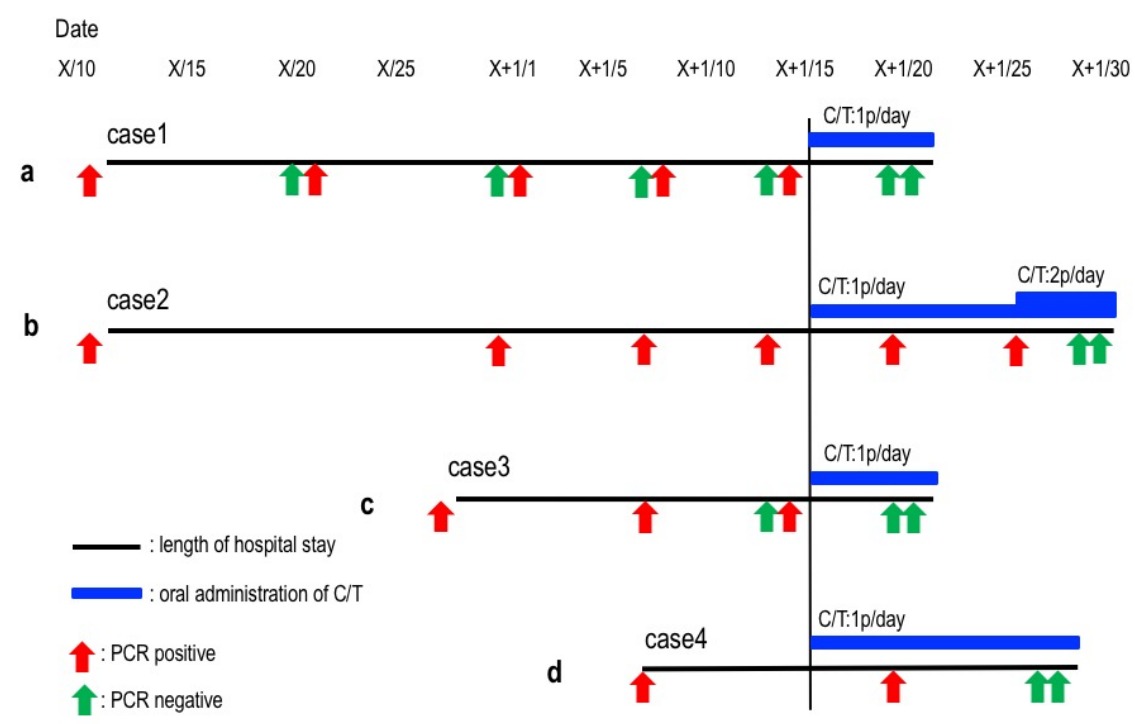

